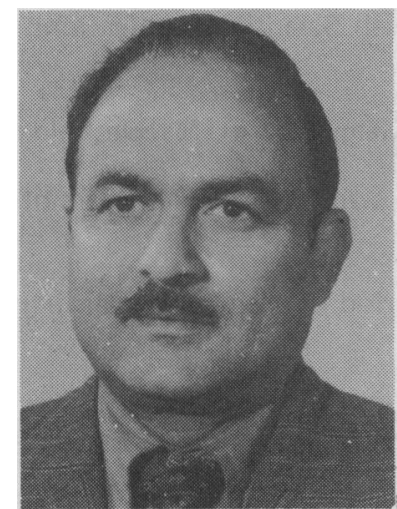

J. L. Bhanot

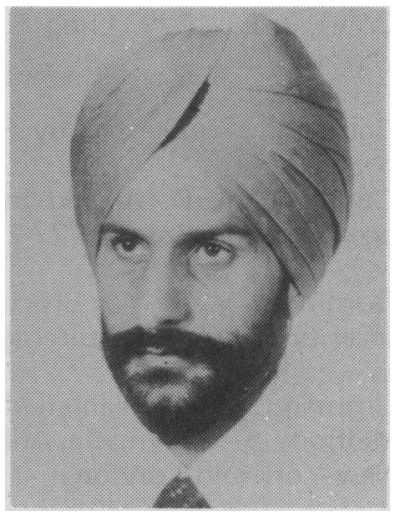

L. S. Sidhu

\title{
MAXIMAL ANAEROBIC POWER IN INDIAN NATIONAL HOCKEY PLAYERS
}

\author{
J. L. BHANOT, MSc (Physiol), LLB, Dip Sports Medicine* and \\ L. S. SIDHU, MSc, PhD, Dip Human Biology (Oxford) * * \\ *Lecturer, Department of Human Biology, Punjabi University, Patiala, Punjab, India \\ * *Professor, Department of Human Biology, Punjabi University, Patiala, Punjab, India
}

\begin{abstract}
Anaerobic power in relation to field position of 90 Indian hockey players has been studied. These players included 10 goalkeepers, 16 backs, 20 half-backs and 44 forwards. The goalkeepers possess maximum and forwards possess minimum anaerobic power while in vertical velocity, the former are the fastest and the latter are the slowest. In body weight the backs are heaviest followed by half-backs, goalkeepers and forwards. Among backs, the lefts are heavier, faster and have more anaerobic power than rights. In half-line players, the centre-half-backs are followed by left-half-backs and right-half-backs both in body weight and anaerobic power, while in vertical velocity, the left-half-backs are the fastest and centre-half-backs are the slowest. Among forwards, the centre-forwards are heaviest with maximum anaerobic power and are followed by inside-forwards and outside-forwards, whereas, in vertical velocity the inside-forwards are fastest followed by centre-forwards and outside-forwards.
\end{abstract}

\section{INTRODUCTION}

Åstrand (1955), Saltin and Åstrand (1967) and Ekblom and Hermansen (1968) have reported data on aerobic and anaerobic power of Swedish Champion athletes; Robinson et al (1937) and Costill (1970) on American athletes; Bannister et al (1960) and Newman et al (1962) on British athletes; Cerretelli and Radovani (1960) on athletes of the Rome Olympic Games and Di Pampero et al (1970) on Mexico Olympian athletes. Very few such studies are available on Indian sportsmen. Bhanot and Sidhu (1981) reported the anaerobic power in National level Indian players specialising in different sportive events. A dominating role of anaerobic power in sprint running and short-distance swimming have been established (Åstrand, 1955; Margaria, 1966; Di Pampero et al, 1970; Robinson, 1937), however, its contribution in the game of hockey which is considered to be an endurance event (Bhanot and Sidhu, 1981; Costill, 1970; Margaria,
1966; Saltin et al, 1967) has not been fully explained. The present study has been taken up with a view to find out whether anaerobic power of a hockey player has got any relationship with his field position.

\section{MATERIALS AND METHODS}

The study has been conducted on 90 hockey players at Netaji Subhas National Institute of Sports (NIS), Patiala. These players were the National Seniors, National Juniors, Combined University and NIS Trainees. They included 10 goalkeepers, 16 backs, 20 half-backs and 44 forwards. Maximal vertical velocity was determined by the technique described by Margaria et al (1966) and Kansal et al (1981). From the maximal vertical velocity and body weight, the mechanical work output has been estimated, Margaria (1966) describing the mechanical work output to be the anaerobic power. 


\section{RESULTS AND DISCUSSION}

Table I shows the number and some other measurements of the hockey players studied.

The goalkeepers, backs and half-backs have been observed to be faster in vertical velocity, heavier in body weight and better in anaerobic power than the forwards. The goalkeepers are lighter in body weight, faster in vertical velocity and possess higher anaerobic power than backs and half-backs. The backs are slower in vertical velocity but have more body weight and anaerobic power than half-backs (Fig. 1).

The goalkeepers, backs and half-backs have to check the opponents in the field for snatching as well as clearing the ball, whereas, there is a tendency on the part of the forwards to possess the ball themselves. The quickness of the former categories helps them in carrying out these functions more efficiently. The lower anaerobic power in forwards may be attributed to the fact that they derive most of the energy aerobically. Thus they are found to be lighter in body weight and slower in vertical velocity. While comparing goalkeepers with backs and half-backs, the former are found to possess maximum anaerobic power which is essential for defending the goal area. Among backs and half-backs, the former are found to possess more anaerobic power due to the same reasons, however, in vertical velocity the half-backs have shown more value than the backs which may perhaps be due to the fact that backs have more body weight than half-backs. The heavier weight of the backs (Table II) may be due to more muscle mass which is required for forceful strokes. Table III gives the values of the parameters studied with right and leftbacks. It is observed that left-backs are significantly faster (Table IV) and possess better anaerobic power than right-backs (Table III, Fig. 2).

The speed and better anaerobic power of the leftbacks compared with the right-backs may be due to their odd field position because they have to avoid the foul of obstruction whenever tackling the opponents and also have to tackle the right-outs of the opponents who would have better anaerobic power and are faster than the left-outs.
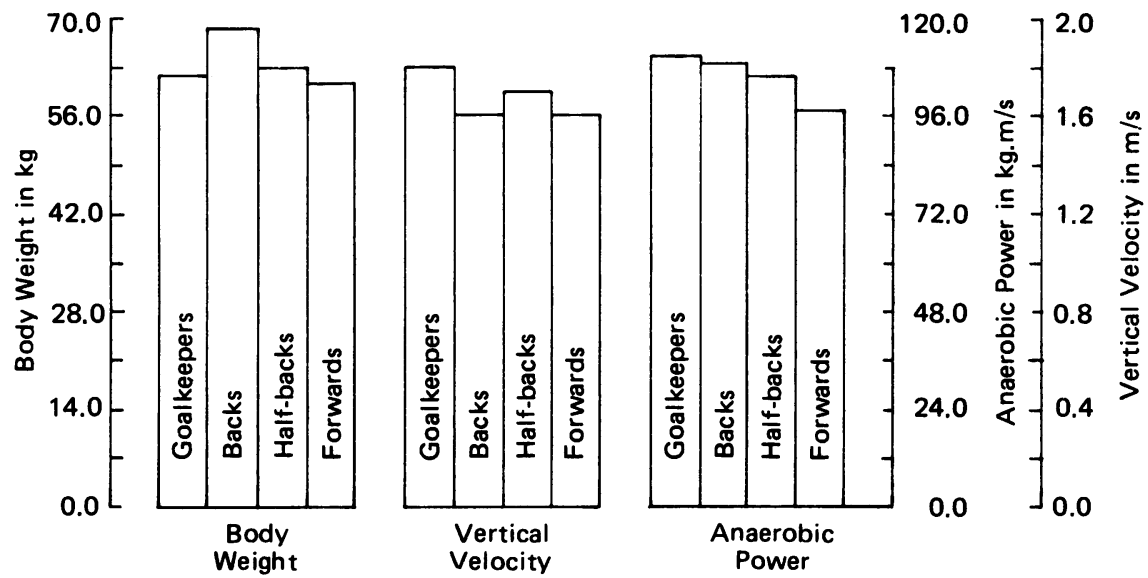

Fig. 1: Histogram indicating the mean values of body weight, vertical velocity and anaerobic power of goalkeepers, backs, half-backs and forwards in hockey.

\section{TABLE I}

Means and standard deviations of body weight, vertical velocity and anaerobic power of goalkeepers, backs, half-backs and forwards in hockey.

\begin{tabular}{|c|c|c|c|c|c|c|c|c|}
\hline \multirow[b]{2}{*}{ Field position } & \multirow[b]{2}{*}{$n$} & \multirow{2}{*}{$\begin{array}{c}\text { Mean } \\
\text { age } \\
\text { years }\end{array}$} & \multicolumn{2}{|c|}{ Body weight } & \multicolumn{2}{|c|}{ Vertical velocity } & \multicolumn{2}{|c|}{ Anaerobic Power } \\
\hline & & & $\begin{array}{c}\text { Mean } \\
\text { kg }\end{array}$ & \pm S.D. & $\begin{array}{l}\text { Mean } \\
\mathrm{m} \cdot \mathrm{s}^{-1}\end{array}$ & \pm S.D. & $\begin{array}{c}\text { Mean } \\
\mathrm{m} \cdot \mathrm{kg}^{-1} \mathrm{~s}^{-1}\end{array}$ & \pm S.D. \\
\hline Goal & 10 & 20.23 & 61.90 & 7.58 & 1.817 & 0.71 & 111.11 & 9.34 \\
\hline Backs & 16 & 21.14 & 68.53 & 8.42 & 1.604 & 0.32 & 109.66 & 14.14 \\
\hline Half-backs & 20 & 21.18 & 63.15 & 7.46 & 1.713 & 0.41 & 106.22 & 11.37 \\
\hline Forwards & 44 & 20.92 & 61.33 & 7.76 & 1.589 & 0.34 & 97.55 & 14.45 \\
\hline
\end{tabular}


Table III also shows the same parameters in right, centre and left-half-backs as in Table I and II. It is evident from the table that out of these three categories centre-half-backs possess best anaerobic power while the right-half-backs the least. In vertical velocity the lefthalf-backs are the fastest followed by right and centrehalf-backs. The body-weight of centre-half-backs is the heaviest and those of right-half-backs is the lightest (Table III, Fig. 3).

\section{TABLE ||}

Values of Student's ' $t$ ' in body weight, vertical velocity and anaerobic power showing inter-comparisons of four important field position players in hockey.

$\begin{array}{lccl}\text { Comparison between } & \text { Body weight } & \begin{array}{c}\text { Vertical } \\ \text { velocity }\end{array} & \begin{array}{c}\text { Anaerobic } \\ \text { Power }\end{array} \\ \begin{array}{l}\text { Goalkeepers and backs } \\ \text { Goalkeepers and }\end{array} & 2.0783^{*} & 0.9260 & 0.3152 \\ \text { half-backs } & 1.6891 & 0.4166 & 1.2255 \\ \text { Goalkeepers and forwards } & 0.2134 & 1.3630 & 3.6948^{* * * *} \\ \text { Backs and half-backs } & 2.0079^{*} & 0.9083 & 0.7908 \\ \text { Backs and forwards } & 2.9875^{* * *} & 0.1666 & 2.9180^{* * *} \\ \text { Half-backs and forwards } & 1.8817 & 1.2400 & 2.5958^{* *}\end{array}$

Statistically significant at $5 \%$ level with probability as follows

* probability $0.05>0.02$

* * probability $0.02>0.01$

** * probability $0.01>0.001$

*** * probability $<0.001$
The centre-half-backs have to play more as backs and, therefore, their body weight and anaerobic power follow the pattern of those of backs. Similarly, the right and left-half-backs have to play more as forward-line players, therefore, their body-weight and anaerobic power are more nearer to those of forward-line players. The significant difference in body weight of centre-half-backs (Table IV) make them the slowest among the half-backs but at the same time this difference is compensated in the case of anaerobic power and thus they possess the best anaerobic power among the half-backs. The lefthalf-backs are faster and possess better anaerobic power than right-half-backs and this difference may be due to the same factors which make the left-backs faster and better in anaerobic power than right-backs.

From Table III, it is evident that amongst the forward line players, the centre-forwards are the heaviest and possess the maximum anaerobic power. The mean values of both these variables show a decrease from centre towards outside position. However, in vertical velocity, the centre-forwards are slower than inside forwards and faster than outside forwards (Table III, Fig. 4).

The outside forwards have to run longer distances while playing than the inside and centre-forwards, and may account for their being lighter in body-weight. The same analogy seems to apply for inside forwards when compared with centre-forwards. The speed of inside forwards may be attributed to the fact that they have to tackle for possession and clearance of the ball much more than the centre-forwards and outside forwards.

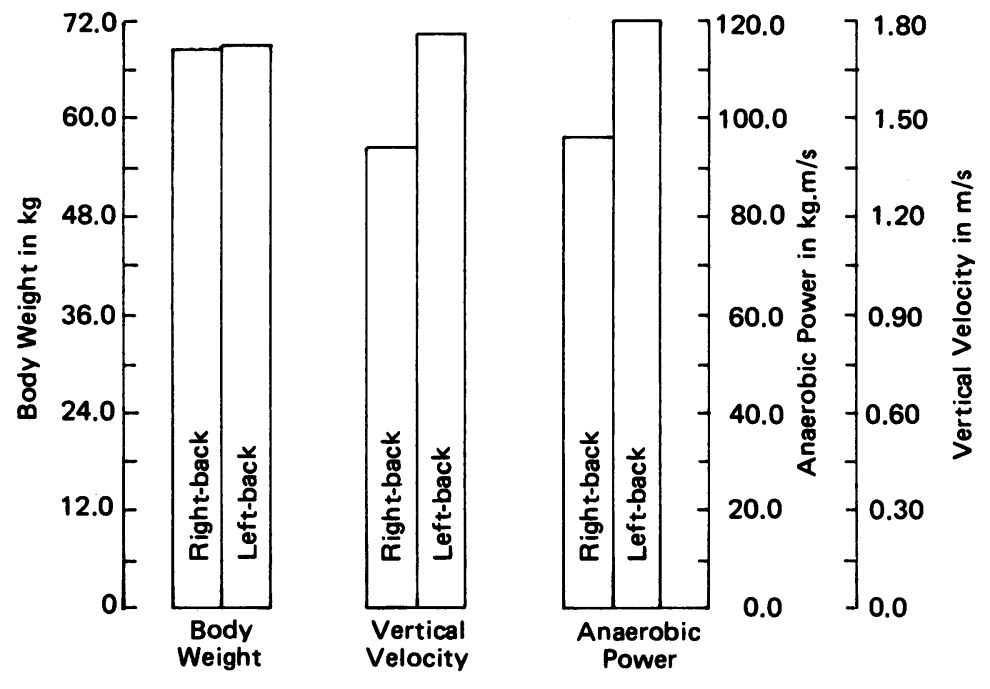

Fig. 2: Histogram indicating the mean values of body weight, vertical velocity and anaerobic power of right and left-backs in hockey. 
TABLE III

Means and standard deviations of body weight, vertical velocity and anaerobic power of different field position players in hockey.

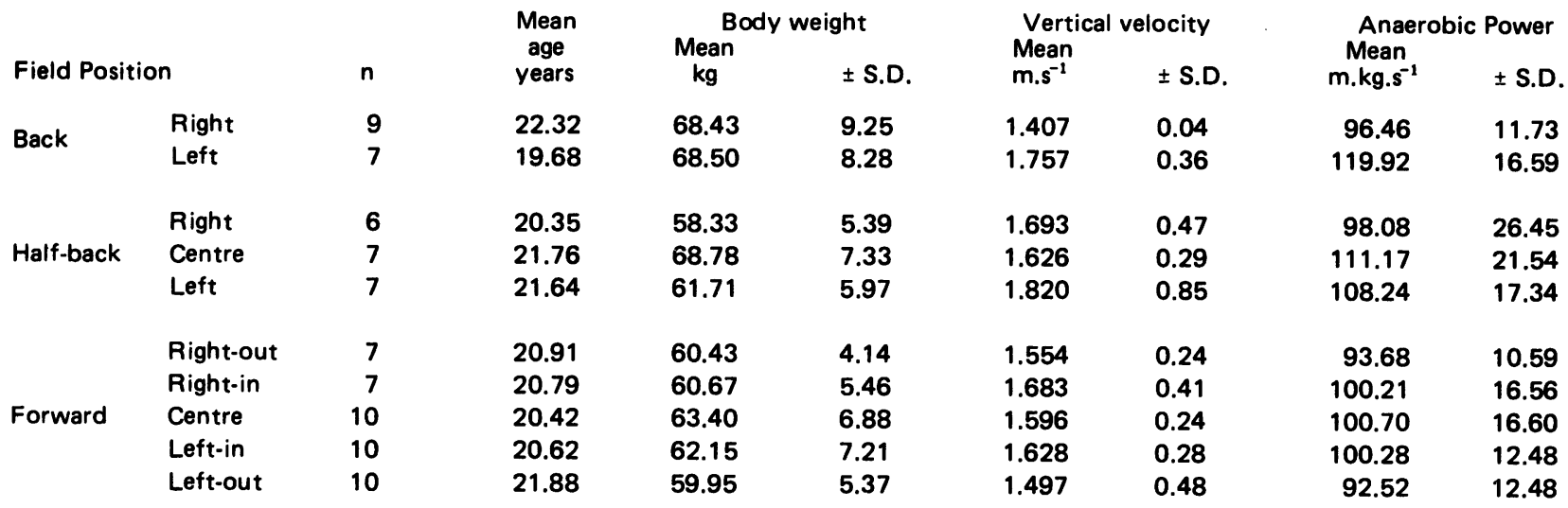

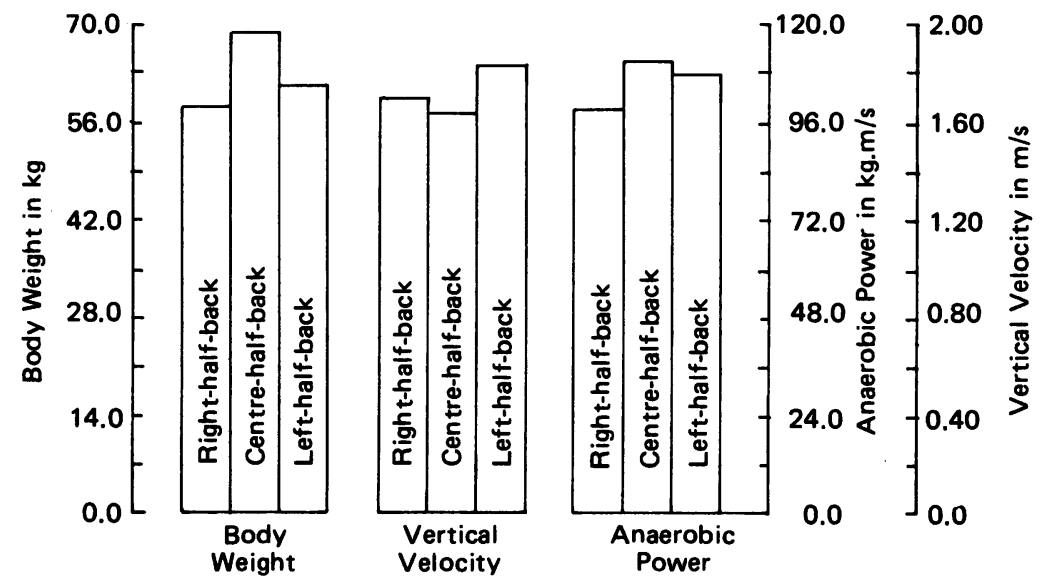

Fig. 3: Histogram indicating the mean values of body weight, vertical velocity and anaerobic power of right, centre and left-half-backs in hockey.

The same reason may apply to the centre-forwards while comparing them with outside forwards for vertical velocity. The body weight may be attributed for the best anaerobic power of the centre-forwards among forwardline players in spite of the fact that they are slower than the inside forwards in vertical velocity. The less vertical velocity and lighter body weight is responsible for the relatively low anaerobic power of the outside forwards.

Thus according to our findings the goalkeepers are the fastest in vertical velocity and possess the best anaerobic power. They are followed by backs in anaerobic power and by half-backs in vertical velocity. The forwards are the slowest in vertical velocity and possess minimum anaerobic power. In body weight the backs are heaviest followed by half-backs, goalkeepers and forwards. In the back-line the lefts have higher anaerobic power with more vertical velocity and body weight than rights. Among half-line players, the centre-half-backs are followed by left-half-backs and right-half-backs both in body weight and anaerobic power, while in vertical velocity, the left-half-backs are the fastest and centrehalf-backs are the slowest. Among forward-line players, the centre-forwards have maximum anaerobic power and body weight followed by inside forwards and outside forwards, whereas, in vertical velocity the inside forwards are fastest followed by centre-forwards and outside forwards. 

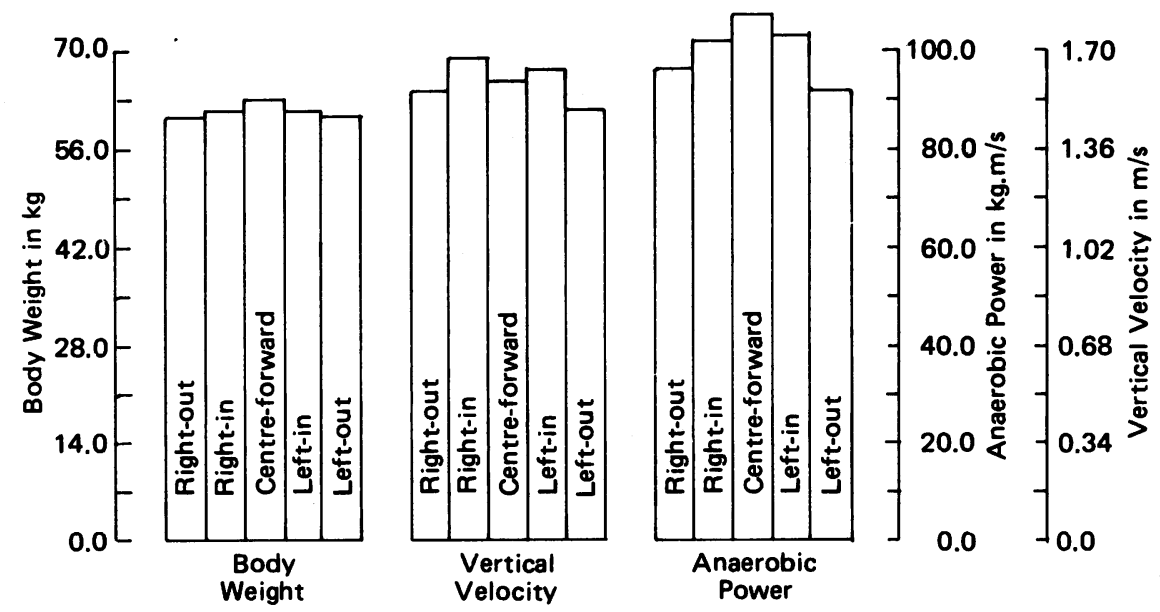

Fig. 4: Histogram indicating the mean values of body weight, vertical velocity and anaerobic power of right-outs, right-ins, centre-forwards, left-ins and leftouts in hockey.

\section{TABLE IV}

Values of Student's ' $t$ ' in body weight, vertical velocity and anaerobic power showing comparison of backs, half-backs and forward line players in hockey.

\begin{tabular}{|c|c|c|c|}
\hline Comparison between & $\begin{array}{l}\text { Body } \\
\text { weight }\end{array}$ & $\begin{array}{l}\text { Vertical } \\
\text { velocity }\end{array}$ & $\begin{array}{c}\text { Anaerobic } \\
\text { Power }\end{array}$ \\
\hline \multicolumn{4}{|l|}{ Backs } \\
\hline Right and Left & 0.0157 & $2.9183 * *$ & $4.1300 * * *$ \\
\hline \multicolumn{4}{|l|}{ Half-backs } \\
\hline Right and Centre & $2.9436^{*}$ & 0.3161 & 0.9871 \\
\hline Right and Left & 1.0730 & 0.3342 & 0.8226 \\
\hline Centre and Left & 1.9638 & 0.5658 & 0.2795 \\
\hline \multicolumn{4}{|l|}{ Forwards } \\
\hline Right-out and Right-in & 0.1395 & 0.7172 & 0.8781 \\
\hline Right-out and Centre & 1.1123 & 0.3890 & 1.0627 \\
\hline Right-out and Left-in & 0.6231 & 0.5350 & 1.1754 \\
\hline Right-out and Left-out & 0.2086 & 0.3166 & 0.2066 \\
\hline Right-in and Centre & 1.1137 & 0.5105 & 0.0607 \\
\hline Right-in and Left-in & 0.6775 & 0.3229 & 0.0098 \\
\hline Right-in and Left-out & 0.0451 & 0.8861 & 1.0341 \\
\hline Centre-forward and Left-in & 0.3968 & 0.2900 & 0.6380 \\
\hline Centre-forward and Left-out & 1.5222 & 0.5841 & 1.2428 \\
\hline Left-in and Left-out & 0.7746 & 0.7717 & 1.3765 \\
\hline
\end{tabular}

Statistically significant at $\mathbf{5 \%}$ level with probability as follows:

* probability $0.02>0.01$

* * probability $0.01>0.001$

* * probability $<0.001$
From the findings, it is clear that at certain field positions, the players are faster in vertical velocity, better in anaerobic power, whereas, at certain other field positions, they are relatively slower and possess less anaerobic power. These field positional differences may be attributed to the offensive and defensive situations in the game of hockey. These positional differences also indicate that at a certain field position, a player derives his energy predominantly from anaerobic sources while at other field position, the player derives his energy predominantly from aerobic sources, thus reflecting that the role of anaerobic power cannot be ruled out in hockey as it is the main source of energy derivation for certain field positions in this game.

\section{ACKNOWLEDGEMENTS}

We are thankful to Mr. R. L. Anand, Director and hockey coaches, specially Mr. Balkishan Singh of the Netaji Subhas National Institute of Sports, Patiala and Mr. Hans Raj Arora and Mr. Gurcharan Singh of the Research Centre for extending their willing co-operation in the data collection of this study. 


\section{REFERENCES}

Åstrand, P. O., 1955 “New records in human power". Nature 176: 1922-1923.

Bhanot, J. L. and Sidhu, L. S., 1981 "Maximal anaerobic power in national level Indian game players". Brit.J.Sports Med. 15: 265-268.

Bannister, R. G., Cotes, J. E., Jones, R. S. and Meade, F., 1960 "Pulmonary diffusion capacity on exercise in athletes and non-athletic subjects". J.Physiol. 152: 66-67.

Cerreteli, P. and Radovani, E. P., 1960 "Il massimo consume di $\mathrm{O}_{2}$ in atteti olimpionici di varie specialita". Boll.Soc.It. Biol.Sper. 36: 1871-1872.

Costill, D. L., 1970 “Metabolic responses during distance running". J.Appl.Physiol. 28: 251-255.

Ekblom, B. and Hermansen, L., 1968 “Cardiac output in athletes”. J.Appl.Physiol. 25: 619-625.

Kansal, D. K., Verma, S. K. and Sidhu, L. S., 1981 “Improvisation of a simple device for measuring human anaerobic power and the study of anaerobic power of national Indian sportsmen and sportswomen". Brit.J.Sports Med. 15: 136-140.

Margaria, R., Aghemo, P. and Rovelli, E., 1966 "Indirect determination of maximal oxygen consumption in man". J.Appl.Physiol. 20: 1070-1073.

Margaria, R., Aghemo, P. and Rovelli, E. 1966 "Measurement of muscular power (anaerobic) in man". J.Appl.Physiol. 21: $1662-1664$.

Newman, Faith, Smalley, B. F. and Thomson, M. L., 1962 "Effect of exercise, body and lung size on co-diffusion in athletes and non-athletes". J.Appl.Physiol. 17: 649-655.

Di Pampero, P. E., Limas, F. P. and Sassi, G., 1970 “Maximal muscular power, aerobic and anaerobic in 116 athletes performing at the XIXth Olympic games in Mexico". Ergonics 13: 665-674.

Robinson, S., Edwards, H. T. and Hill, D. B., 1937 "New records in human power". Science 85: 409-410.

Saltin, B. and Åstrand, P. O., 1967 “Maximal oxygen uptake in athletes”. J.Appl.Physiol. 23: 353-358. 